www.jmscr.igmpublication.org

Impact Factor (SJIF): 6.379

Index Copernicus Value: 71.58

ISSN (e)-2347-176x ISSN (p) 2455-0450

crossref DOI: https://dx.doi.org/10.18535/jmscr/v6i5.171

Journal Of Medical Science And Clinical Research

IGM Publication

An Official Publication of IGM Publication

\title{
Comparing the effects of Bupivacaine and Ropivacaine Instillation for Postoperative Analgesia in Patients Undergoing Lumbar Spine Surgery: A Prospective Randomised Double Blind Study
}

Authors

\author{
Manoj Kumar ${ }^{1}$, Jay Brijesh S. Yadav ${ }^{2 *}$, Dimple Saini ${ }^{3}$
}

${ }^{1}$ Associate Professor, Department of Anaesthesiology, UPUMS, Saifai, Etawah .UP, India

${ }^{2}$ Lecturer, Department of Anaesthesiology, UPUMS, Saifai, Etawah, UP, India

${ }^{3}$ Resident, Department of Anaesthesiology, UPUMS, Saifai, Etawah, UP, India

Corresponding Author

Jay Brijesh Singh Yadav

Department of Anaesthesiology, Uttar Pradesh University of Medical Sciences, Saifai, Etawah, U.P. India Email:drjaybrijesh@gmail.com

\begin{abstract}
Introduction: Laminectomy is associated with considerable postoperative pain. Providing analgesia locally in the area of surgical trauma, with minimal systemic side effects has become an integral part of multimodal analgesia. The objective of this study is to compare the effects of bupivacaine and ropivacaine instillation for postoperative analgesia in patients undergoing lumbar spine surgery.

Methods: The study was conducted in a double blind manner. 40 ASA I \& II patients scheduled for lumbar laminectomy were randomly divided into two groups to receive either $20 \mathrm{ml}(0.25 \%)$ of bupivacaine (group $B)$ or ropivacaine $(0.25 \%)$ instillation into the wound after securing hemostasis. After a dwell time of 60 sec the wound was closed in layers without mopping or suctioning. After extubation, the pain scores were evaluated by Numerical rating scale at 0 hours i.e., immediately after extubation and then at every 1 hour up to first 8 hours and then at every 6 hours till 24 hours and also the time for first demand of analgesia, number of analgesic demands and the total amount of analgesia consumed were noted by an independent observer.

Results: The area under curve for mean pain score over 24 hrs time period on the basis of NRS scale was $46.8 \pm 5.84$ in ropivacaine group $(R)$ and $44.78 \pm 5.36$ in bupivacaine group $(B)$ with $p=0.26$. The duration of analgesia and number of demands and the amount of analgesia consumed was also found statistically not significant.

Conclusion: Surgical wound instillation with bupivacaine and ropivacaine provided better analgesic effect and safe postoperative analgesia in patients undergoing laminectomy surgeries.
\end{abstract}

\section{Introduction}

Lumbar spine surgery is a commonly performed procedure in neurosurgical and orthopaedic practice. Commonly performed spinal surgeries include laminectomies, discectomies, spinal fusions, instrumentations, scoliosis corrections, and spinal tumor excision. Patients usually suffer significant pain after surgery. ${ }^{1}$ Postoperative pain 
relief helps in early mobilization, initiation of physiotherapy, provides satisfaction to the patients, preventing the development of chronic pain and plays an important role in reducing the morbidity and mortality. ${ }^{2-3}$ Currently several postoperative analgesic options are available. Intravenous opioids, NSAIDs, intrathecal administration of opioids and local anaesthetics have been evaluated. Most of these techniques may be limited by potentially high failure rates, high cost, technically challenging, and labor intensive, adverse /toxic effects, and procedurerelated complications. Instillation of local anaesthetic drug into the wound was found to provide postoperative analgesia in certain surgical procedures like hernia repair and laparoscopic cholecystecytomy. ${ }^{4}$ Simple technique of instillation of wound with bupivacaine or ropivacaine and leaving a contact time of 60 seconds may alleviate postoperative pain following lumbar laminectomy. The probable mechanism of pain relief could be due to the anaesthetic effect of bupivacaine acting on the pain receptors distributed in the soft tissues and the nerve endings exposed in the wound right from the skin to the dura meninge (skin, paraspinal muscle, posterior longitudinal ligament, dorsal annulus, facet joint capsule, nerve root which was under compression and the spinal meninges the dura supplied by recurrent nerve of Von Luschka). ${ }^{5}$ Recently, Rushdi et al. reported that the wound was infused with a solution of ropivacaine $0.4 \%$, suggesting the potential for the use of this method in major spinal surgery ${ }^{6}$. The present study was designed to evaluate and compare the effectiveness of wound instillation technique for postoperative analgesia after lumbar spine discectomy and laminectomy by using $20 \mathrm{ml}$ bupivacaine $(0.25 \%)$ or $20 \mathrm{ml}$ ropivacaine $(0.25 \%)$.

\section{Materials and Method}

After obtaining approval of the institutional Ethics Committee and informed consent of the patients, a randomized double-blind study was conducted on
40 patients of either sex and ASA I \& II physical status, scheduled to undergo single level lumbar laminectomy under general anaesthesia. Patients with ASA grade III-IV, instrumentation due to spondylolisthesis or spinal stenosis, and planned to have multiple distance or double site laminectomy, patients with prior lumbar disc surgery, prior neurological deficits, preoperative opioid use or any history of substance abuse or on steroids, infection, local anaesthetics allergy, bleeding, cerebrospinal fluid leak, were excluded from the study. Patients were randomly allocated in two groups of twenty each using sealed opaque envelopes. Group $\mathrm{R}$ received wound site instillation with $20 \mathrm{ml}$ of $0.25 \%$ ropivacaine $(n=20)$. Group B received wound site instillation with $20 \mathrm{ml}$ of $0.25 \%$ bupivacaine $(n=20)$. All patients were examined pre-operatively and details regarding clinical history, general physical examination were recorded and all routine investigations were carried out. All patients were assessed the day before surgery and instructed how to rate the intensity of pain using numerical rating scale (NRS), a scale of zero to ten, where 0 $=$ no pain and $10=$ worst pain. Upon arrival in the operating room, $18 \mathrm{G}$ intravenous cannula was inserted in a peripheral vein and a Ringer lactate solution was started at $6 \mathrm{ml} / \mathrm{kg}$. Monitoring of non-invasive blood pressure (NIBP), heart rate, electrocardiogram, SpO2 monitoring and Etco2 was started and carried out throughout the perioperative period. All patients were premedicated with injection Glycopyrrolate $(0.2 \mathrm{mg})$, injection fentanyl $(2 \mathrm{mcg} / \mathrm{kg})$, injection midazolam $(0.25 \mathrm{mg} / \mathrm{kg})$. After $3 \mathrm{~min}$ of preoxygenation, anaesthesia was induced with injection propofol 2 $\mathrm{mg} / \mathrm{kg}$ i.v ; injection succinylcholine $1.5 \mathrm{mg} / \mathrm{kg}$ i.v. to facilitate endotracheal intubation. Maintenance of anaesthesia was carried out using $67 \% \mathrm{~N}_{2} \mathrm{O}$ in $33 \% \quad \mathrm{O}_{2}$ and halothane $0.5 \%$ using controlled ventilation. Neuromuscular blockade was achieved using vecuronium $0.08-0.12 \mathrm{mg} / \mathrm{kg}$. Intra operative analgesia was provided with Paracetamol 1 gram IV. At the end of surgical procedure and when haemostasis was achieved, 
patients in group (R) received instillation of $20 \mathrm{ml}$ ropivacaine $(0.25 \%)$ and group (B) received $20 \mathrm{ml}$ $(0.25 \%)$ bupivacaine. All the drugs were allowed to remain in the wound for a dwell time of 60 seconds. Postoperative pain was assessed by an independent observer blinded to the study by numeric rating scale (NRS), first at 0 hours i.e., immediately after extubation and then at every 1 hour up to first 8 hours and then at every 6 hours till 24 hours. The duration of analgesia was considered from the time the study drug was instilled to the time for first demand of rescue analgesia When pain score reach $\geq 4$ point on numeric rating scale, inj. diclofenac $75 \mathrm{mg}$ deep intramuscular was given as rescue analgesia.
Duration of analgesia, total analgesic requirement and hemodynamic variables viz, heart rate, mean arterial blood pressure in 24 hours were also recorded.

\section{Statistical Analysis}

At the end of the study, results were represented as Mean $\pm \mathrm{SD}$ and percentage changes. The statistical analysis of quantitative data $($ Mean \pm SD) between the groups was done by student ' $\mathrm{t}$ ' test. The statistical analysis of qualitative data $(\mathrm{N} \%)$ between the groups is done by using Fischer exact test. P-value $<0.05$ was statistically significant. All the analysis was done using SPSS Statistical package version 20.0.

\section{Results}

Table 1: Demographic data of the patients in study groups

\begin{tabular}{|l|c|c|c|}
\hline \multirow{2}{*}{ Parameters } & Group R & Group B & p value \\
\cline { 2 - 4 } & $\mathrm{n}=20$ & $\mathrm{n}=20$ & R vs B \\
\hline Age & $37.45 \pm 7.53$ & $38.5 \pm 10.06$ & $0.71(\mathrm{NS})$ \\
\hline Sex & & & \\
\hline Male & $13(65 \%)$ & $13(65 \%)$ & $1.00(\mathrm{NS})$ \\
Female & $7(35 \%)$ & $7(35 \%)$ & \\
\hline Weight & $65.75 \pm 12.37$ & $68.5 \pm 10.29$ & $0.45(\mathrm{NS})$ \\
\hline Height & $164.4 \pm 9.49$ & $166.7 \pm 9.11$ & $0.44(\mathrm{NS})$ \\
\hline 1 & $16(80 \%)$ & $16(80 \%)$ & $1.00(\mathrm{NS})$ \\
2 & $04(20 \%)$ & $04(20 \%)$ & \\
\hline
\end{tabular}

Table 2: Comparison of patients data among the groups

\begin{tabular}{|l|c|c|c|}
\hline Parameters & Group R & Group B & P value \\
\cline { 2 - 4 } & $\mathrm{n}=20$ & $\mathrm{n}=20$ & R vs B \\
\hline Duration of surgery (minutes) & $105.15 \pm 10.03$ & $107.75 \pm 8.85$ & $0.39(\mathrm{NS})$ \\
\hline Duration of analgesia (hours) & $12.15 \pm 1.49$ & $12.39 \pm 1.56$ & $0.62(\mathrm{NS})$ \\
\hline Amount of analgesia (mg) & $97.5 \pm 35.26$ & $93.75 \pm 33.32$ & $0.73(\mathrm{NS})$ \\
\hline Number of demands & & & \\
\hline 1 & $14(70 \%)$ & $15(75 \%)$ & $0.84(\mathrm{NS})$ \\
2 & $6(30 \%)$ & $5(25 \%)$ & \\
3 & $0(0 \%)$ & $0(0 \%)$ & \\
\hline
\end{tabular}

Table 3: Comparison of heart rate between study groups

\begin{tabular}{|l|c|c|c|}
\hline HR & Group R & Group B & p-value \\
\hline Mean \pm SD & $\mathrm{n}=20$ & $\mathrm{n}=20$ & $\mathrm{R}$ vs B \\
\hline 0 hour & $88.35 \pm 7.44$ & $86.35 \pm 5.21$ & 0.33 \\
\hline 1 hour & $83.85 \pm 9.77$ & $85.15 \pm 8.12$ & 0.65 \\
\hline 2 hours & $81.65 \pm 8.75$ & $83.4 \pm 8.05$ & 0.51 \\
\hline 3 hours & $80.9 \pm 8.57$ & $83.25 \pm 7.16$ & 0.35 \\
\hline 4 hours & $81.4 \pm 9.53$ & $83.45 \pm 8.27$ & 0.47 \\
\hline 5 hours & $82.25 \pm 9.17$ & $83.75 \pm 7.28$ & 0.57 \\
\hline 6 hours & $83.2 \pm 10.36$ & $83.45 \pm 8.29$ & 0.93 \\
\hline 7 hours & $86.15 \pm 9.92$ & $85.8 \pm 7.07$ & 0.90 \\
\hline 8 hours & $88.7 \pm 10.69$ & $87.95 \pm 8.07$ & 0.80 \\
\hline 14 hours & $94.05 \pm 7.81$ & $90.6 \pm 4.76$ & 0.10 \\
\hline 20 hours & $90.65 \pm 10.02$ & $90.55 \pm 8.21$ & 0.97 \\
\hline 24 hours & $91.2 \pm 10.25$ & $91.7 \pm 7.97$ & 0.86 \\
\hline
\end{tabular}


Fig-1: Line diagram showing heart rate changes among groups

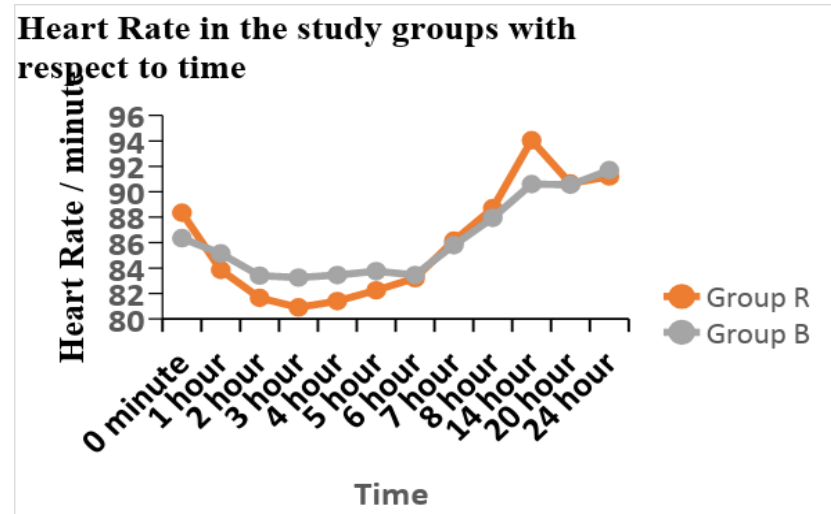

Table 4: Comparison of mean arterial pressure between study groups

\begin{tabular}{|l|c|c|c|}
\hline MAP & Group R & Group B & p-value \\
\hline Mean \pm SD & $\mathrm{n}=20$ & $\mathrm{n}=20$ & $\mathrm{R}$ vs B \\
\hline 0 hour & $88.3 \pm 4.75$ & $88.7 \pm 5.18$ & 0.80 \\
\hline 1 hour & $85.5 \pm 3.89$ & $86.3 \pm 4.29$ & 0.54 \\
\hline 2 hours & $86.0 \pm 5.30$ & $86.1 \pm 5.28$ & 0.95 \\
\hline 3 hours & $85.5 \pm 5.30$ & $86.25 \pm 5.24$ & 0.66 \\
\hline 4 hours & $86.1 \pm 4.67$ & $86.4 \pm 5.02$ & 0.85 \\
\hline 5 hours & $86.6 \pm 4.81$ & $87.0 \pm 5.35$ & 0.81 \\
\hline 6 hours & $86.1 \pm 4.85$ & $87.1 \pm 5.31$ & 0.54 \\
\hline 7 hours & $86.8 \pm 4.38$ & $87.4 \pm 4.53$ & 0.67 \\
\hline 8 hours & $88.1 \pm 5.67$ & $88.25 \pm 5.55$ & 0.93 \\
\hline 14 hours & $92.8 \pm 5.24$ & $92.85 \pm 4.51$ & 0.97 \\
\hline 20 hours & $90.9 \pm 5.28$ & $90.95 \pm 4.77$ & 0.97 \\
\hline 24 hours & $90.7 \pm 4.68$ & $90.7 \pm 4.31$ & 1.00 \\
\hline
\end{tabular}

Fig- 2: Line diagram showing pattern of MAP in the study groups with respect to time

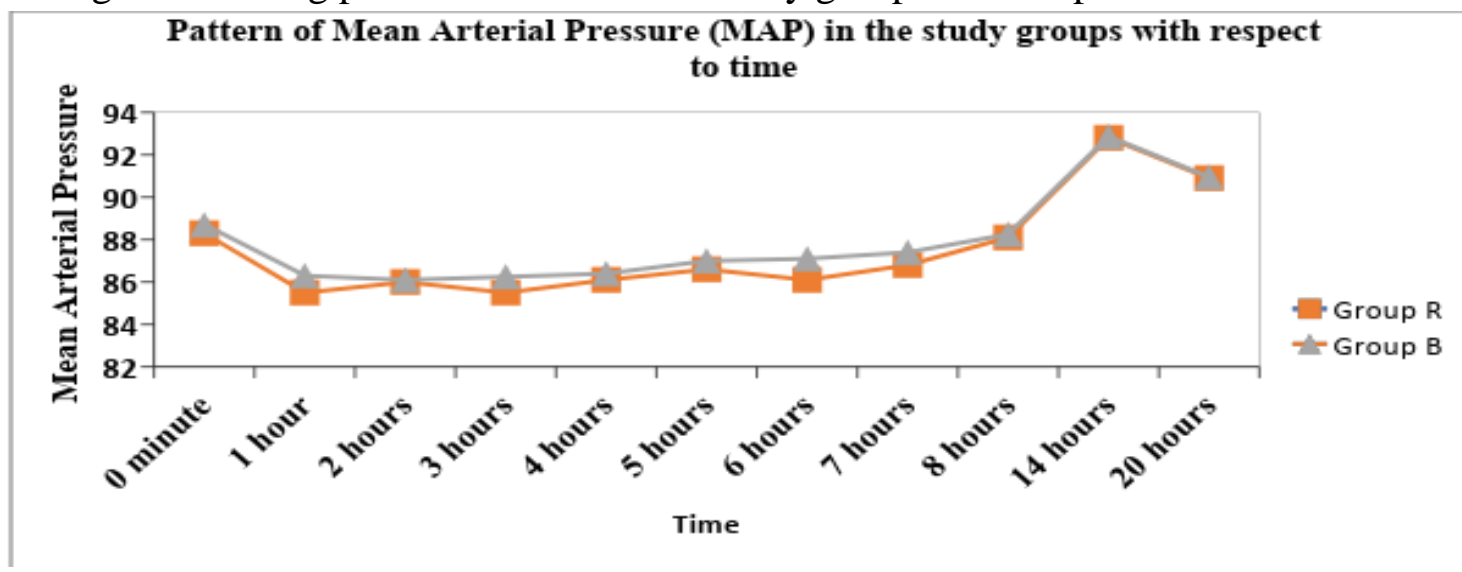

Table 5: Comparison of NRS score between study groups

\begin{tabular}{|l|c|c|c|}
\hline NRS & Group R & Group B & p-value \\
\hline Mean \pm SD & $\mathrm{n}=20$ & $\mathrm{n}=20$ & $\mathrm{R}$ vs B \\
\hline 0 hour & $0 \pm 0$ & $0 \pm 0$ & - \\
\hline 1 hour & $0.1 \pm 0.3$ & $0.55 \pm 0.5$ & $0.001^{*}$ \\
\hline 2 hours & $0.25 \pm 0.4$ & $0.65 \pm 0.5$ & $0.008^{*}$ \\
\hline 3 hours & $0.7 \pm 0.5$ & $0.85 \pm 0.4$ & 0.30 \\
\hline 4 hours & $0.95 \pm 0.4$ & $1.0 \pm 0$ & 0.58 \\
\hline 5 hours & $1.3 \pm 0.5$ & $1.2 \pm 0.4$ & 0.49 \\
\hline 6 hours & $1.7 \pm 0.5$ & $1.3 \pm 0.5$ & $0.01^{*}$ \\
\hline 7 hours & $1.9 \pm 0.3$ & $1.8 \pm 0.4$ & 0.38 \\
\hline 8 hours & $2.6 \pm 0.5$ & $2.2 \pm 0.4$ & $0.008^{*}$ \\
\hline 14 hours & $2.7 \pm 0.8$ & $2.5 \pm 1.0$ & 0.49 \\
\hline 20 hours & $2.1 \pm 0.7$ & $2.1 \pm 0.8$ & 1.00 \\
\hline 24 hours & $2.2 \pm 0.5$ & $2.2 \pm 0.6$ & 1.00 \\
\hline
\end{tabular}


Fig-3: Line diagram showing Pattern of NRS in the study groups with respect to time

$$
\begin{aligned}
& \text { Pattern of NRS in the study groups } \\
& \text { with respect to time }
\end{aligned}
$$
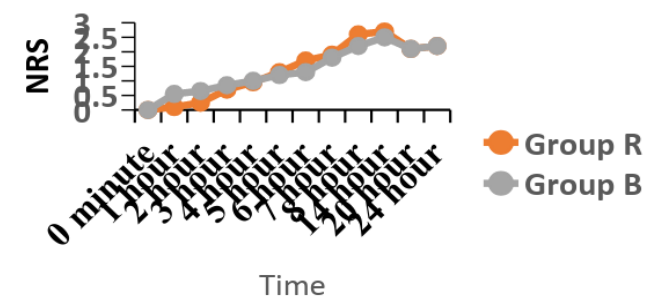

Fig-4: Bar diagram showing pattern of NRS among study groups.

Pattern of NRS in the study groups with respect to time

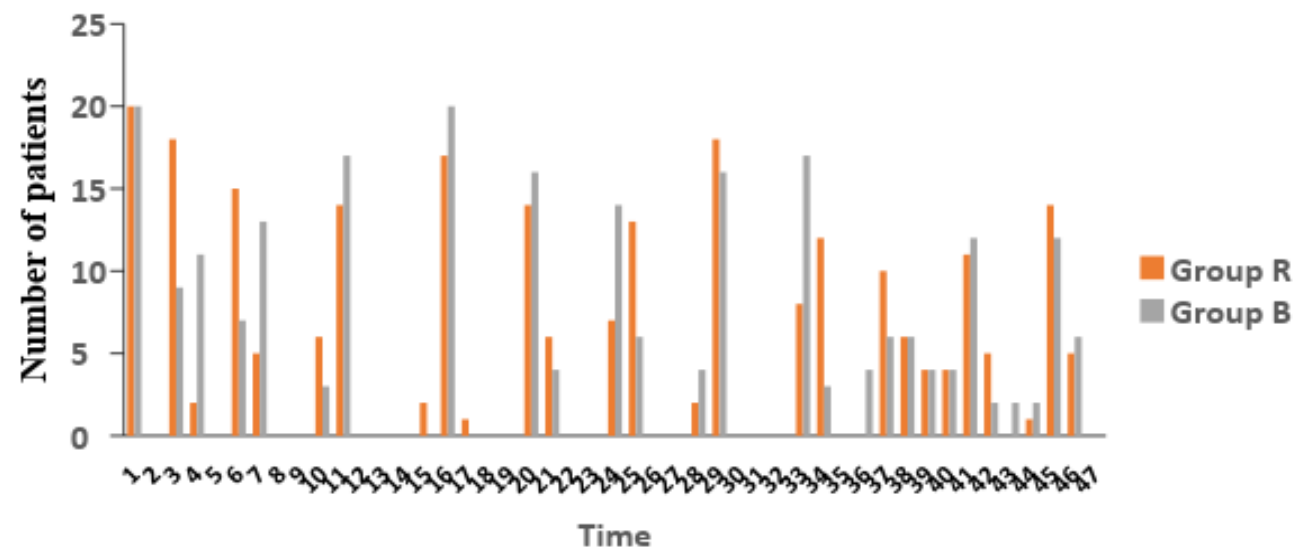

Table 6: Area under curve for NRS among study groups

\begin{tabular}{|l|c|c|c|}
\hline \multirow{2}{*}{ Parameters } & Group R & Group B & p-value \\
\cline { 2 - 4 } & $\mathrm{n}=20$ & $\mathrm{n}=20$ & $\mathrm{R}$ vs B \\
\hline Area under curve (NRS) & $46.8 \pm 5.84$ & $44.78 \pm 5.36$ & 0.26 \\
\hline
\end{tabular}

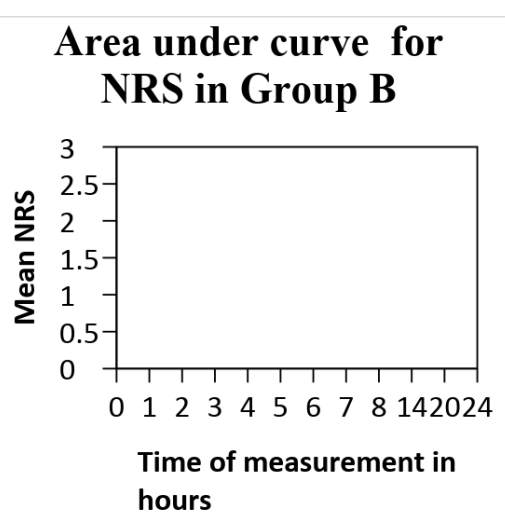

\section{Discussion:}

In our study the demographic data with respect to age, sex, ASA grade and duration of surgery were comparable among all the groups (table 1). In the current study, the study drug was instilled and allowed a dwell time of 60 seconds. The subjects were observed for varying parameters to assess

\section{Area under curve for NRS} in Group $\mathbf{R}$

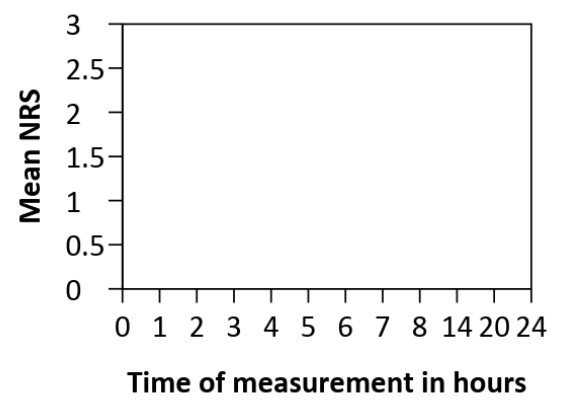

the effects on, duration of analgesia, number of demands, amount of rescue analgesic requirement, hemodynamic changes and NRS pain score over a period of 24 hours (table2,3,4,5). The pain scores were low at all points of time in the study groups. We have taken area under curve for mean pain score over $24 \mathrm{hrs}$ time period on the basis of NRS 
scale and it was $46.8 \pm 5.84$ in ropivacaine group (R) and 44.78 \pm 5.36 in bupivacaine group (B) (table 6) . However, when we compared group $\mathrm{R}$ with group B statistically no significant difference was found $(\mathrm{p}=0.26)$. Mean duration of analgesia in group $\mathrm{R}$ and group B were $12.15 \pm 1.49$ hours and $12.39 \pm 1.56$ hours. There was statistically no significant difference found when ropivacaine (R) group was compared with bupivacaine (B) group (p-0.62). The demands of rescue analgesia in ropivacaine group (group $\mathrm{R}$ ) was one time in 14 $(70 \%)$ patients and two times in $6(30 \%)$ patients. In bupivacaine (group B) it was one time in 15 (75\%) patients and two times in $5(25 \%)$ patients. Number of demands were statistically not significant when group $\mathrm{R}$ was compared with group B ( $\mathrm{p}-0.84)$. In ropivacaine group $(\mathrm{R})$ mean amount of rescue analgesia was $97.5 \pm 35.26 \mathrm{mg}$ and in bupivacaine group (B) was $93.75 \pm 33.32$ $\mathrm{mg}$ respectively. There was statistically no significant difference when group $R$ was compared with group B ( $p-0.73)$. The results of our study showed that pain score was less in ropivacaine group (R) and bupivacaine group (B) but found to be statistically not significant $(\mathrm{p}=0.26)$. The findings in our study correlates to the study done by Hernández_Palazón $\mathrm{J}_{\text {et }} \mathrm{al}^{7}$ in 2001 who found that infiltration of the surgical wound with $0.25 \%$ bupivacaine or $0.25 \%$ ropivacaine was similarly effective for treatment of pain after lumbar disk laminectomy. In their results the mean time until the first request for analgesia was significantly longer in bupivacaine group than in ropivacaine or control group (164 $+/-53 \mathrm{~min}$ versus $68+/-31$ and $38+/-14 \mathrm{~min}$, respectively). The difference could be due to paracetamol 1gram i.v. given during intraoperative period. In another similar study done by Kucuk C et $a l^{8}$ in 2007 found intraperitoneal instillation of $100 \mathrm{mg}$ bupivacaine, $100 \mathrm{mg}$ ropivacaine, or $150 \mathrm{mg}$ ropivacaine at the end of a laparoscopic cholecystectomy significantly reduced the morphine consumption during the first 24 hour. However, for preventing postoperative pain $150 \mathrm{mg}$ ropivacaine proved to be significantly more effective than either $100 \mathrm{mg}$ bupivacaine or $100 \mathrm{mg}$ ropivacaine. Cherian and co authors ${ }^{9}$ in their study evaluating the efficacy of wound infiltration with bupivacaine after lumbar laminectomy found significant analgesia compared to placebo group. the mean time before administration of the first dose of analgesic postoperatively in the bupivacaine and placebo recipients was 807.7 (567.6) minutes and 181.4 (110.1) minutes. In our study mean duration of analgesia in ropivacaine group (R) $12.15 \pm 1.49$ hours and in bupivacaine group (B) was $12.39 \pm$ 1.56 hours respectively. But there was no significant difference when ropivacaine (R) group was compared with bupivacaine (B) group (p0.62 ). In another study by milligan et $a l^{10}$ where patients received injection of $10 \mathrm{ml}$ of $0.5 \%$ bupivacaine into the wound found less pain scores and longer duration of analgesia following lumbar discectomy. Padmaja Durga et al ${ }^{11}$ in 2015 studied role of wound instillation with bupivacaine through surgical drains for postoperative analgesia in modified radical mastectomy and their results also showed that statistically significant less pain in bupivacaine group. The mean duration of analgesia in the bupivacaine group was $14.6 \mathrm{~h}, 10.3$ in the saline group and $4.3 \mathrm{~h}$ in the control group. The rescue analgesic requirement was higher in control group (C) than bupivacaine (B) group with mean $\pm \mathrm{SD}$ $146.2 \pm 101 \mathrm{mg}$ and $36 \pm 43 \mathrm{mg}$ respectively ( $\mathrm{p}<$ 0.0001 ). This study is in close agreement to our study. The pain scores were low at all points of time in the study group and the mean time before administration of the first dose of analgesic postoperatively lower in study groups however longer in bupivacaine group compared to ropivacaine group but difference is statistically not significant. The amount of rescue analgesia requirement is less in bupivacaine group than ropivacaine group but is statistically not significant.

Margherita Bianconi et al ${ }^{12}$ in 2004 conducted a study to assess the pharmacokinetics and efficacy of ropivacaine continuous wound instillation after 
spine fusion surgery and found less pain score in ropivacaine group. In another similar study done by Nevan $M$ et al ${ }^{96}$ in 2011 on sixty patients scheduled for cervical laminectomy with fixation surgery and found pain score during the first $60 \mathrm{~h}$ postoperatively on visual analog scale was lower in bupivacaine group when compared to control group and results were found statistically significant $\left(\mathrm{p}<0.05\right.$. Neha $T$ das et al ${ }^{13}$ in 2017 assess the effects of intraperitoneal bupivacaine and ropivacaine versus placebo on postoperative pain after laparoscopic cholecystectomy. They concluded that ropivacaine $(0.375 \%)$ was longer acting than bupivacaine $(0.25 \%)$. However, in our study longer duration of analgesia observed in bupivacaine group compared to ropivacaine group but difference is not significant. This may be due to higher concentration $(0.375 \%)$ being used in the study. Andrei Goldstein, Patrick Grimault et $a l{ }^{14}$ conducted a study to test the hypothesis that local anaesthetics instilled at the end of laparoscopic gynaecologic procedures are able to prevent postoperative pain at wake-up and during the first $24 \mathrm{~h}$. They found that the rescue analgesia (morphine) consumption at wake-up and over the first $24 \mathrm{~h}$ was significantly lower $(P, 0.05)$ in bupivacaine group (mean, $0.92 \mathrm{mg}$ at wake-up; $3.08 \mathrm{mg}$ over $24 \mathrm{~h}$ ) and in ropivacaine group (mean, $0.25 \mathrm{mg}$ at wake-up; $0.69 \mathrm{mg}$ over $24 \mathrm{~h}$ ), than in normal saline group (mean, $4.18 \mathrm{mg}$ at wake-up; $12.93 \mathrm{mg}$ over $24 \mathrm{~h}$ ). In our study the mean arterial pressure, heart rate were measured over 24 hrs time periods. The variation in heart rate and mean arterial pressure between the groups does not show statistically significant difference ( $p>0.05)$. The results correlate to the study done by Agrawal $S$ et al ${ }^{15}$ who evaluated postoperative pain relief with intra-peritoneal bupivacaine instillation in laparoscopic cholecystectomy. The observed mean heart rate, systolic blood pressure, diastolic blood pressure between both groups was statistically not significant. In another similar study done by $B \quad l$ Yolanda-prieto et al ${ }^{16}$ to compare the effectiveness of $7.5 \%$ ropivacaine instillation versus infiltration after radical mastectomy on 20 female patients divided into two groups. They found statistically no significant difference in systolic and diastolic blood pressure between study groups.

The rationale for choosing the instillation route is to block the afferent signalling and potentially modifying nociception and provides analgesia. The local anaesthetic inhibits nociception by affecting nerve membrane associated proteins and by inhibiting the release and action of prostaglandins and other agents that sensitize or stimulate the nocicepters and contribute to inflammation. ${ }^{15}$ However, absorption from dura meninge surface may also occur, which may be a further mechanism of analgesia.

\section{Conclusion}

The patients who received either ropivacaine or bupivacaine wound instillation had better pain control at all time interval, longer duration of analgesia, less amount of rescue analgesia required. The wound instillation technique is simple, safe and effective in management of acute pain after lumbar laminectomy and can be used as one among the multimodal armamentarium in pain management.

\section{Financial support and sponsorship: Nil Conflict of interest: nil}

\section{References}

1. Cherian MN, Mathews MP, chandy MJ: Local wound infiltration with bupivacaine in lumbar laminectomy. Surg Neur; 47(2):120-2, 1997.

2. DeVine J, Norvell DC, Ecker E, Fourney DR, Vaccaro A, Wang J, Andersson G (2011) Evaluating the correlation and responsiveness of patient-reported pain with function and quality-of-life outcomes after spine surgery. Spine (Phila Pa 1976) 36(21 Suppl): S69-S74. doi:10.1097/BRS.0b013e31822ef6de.

3. Herroeder S, Pecher S, Schonherr ME, Kaulitz G, Hahnenkamp K, Friess H, 
Bottiger BW, Bauer H, Dijkgraaf OG, Durieux ME, Hollmann MW. Systemic lidocaine shortens length of hospital stay after colorectal surgery: a double-blinded, randomized, placebo-controlled trial. Ann Surg 2007; 246:192-200.

4. Yokoyama M, Mizobuchi S, Nagano O, Fujii H, Yamashita M, Hirakawa M.The effects of epidural insertion site and surgical procedure on plasma lidocaine concentration. Anesthesia and Analgesia 2001; 92: 470-5.

5. Jonnavithula N, Khandekia H,Durga P, Ramachandran G. Role of wound instillation with Bupivacaine for postoperative analgesia following lumbar laminectomy. M.E.J.Anaesth 2015; 23:193-98.

6. Rushdi T, Kholeif A, Ibrahim M (2011) Ropivacaine $0.4 \%$ iontophoresis versus continuous catheter infusion after iliac crest bone grafting in lumbar spine surgery. Egypt J Anaesth 27:261-266.

7. Hernández-Palazón J, Tortosa Serrano JA, Burguillos López S, Molero Molero E: Infiltration of the surgical wound with local anaesthetic for postoperative analgesia in patients operated on for lumbar disc herniation. Comparative study of ropivacaine and ,bupivacaine. Rev Esp Anestesiol Reanim; Jan, 48(1):17-20, 2001.

8. Canan Kucuk, Nihal Kadiogullari, Ozgur Canoler, and Serpil Savl. A placebocontrolled comparison of bupivacaine and ropivacaine instillation for preventing postoperative pain after laparoscopic cholecystectomy. Surgery today. 2007;37(5):396-400.

9. Cherian MN, Mathew MP, Chandy MJ. Local wound infiltration with bupivacaine in lumbar laminectomy. Surgical neurology, Feb , 47(2):120-2, 1997.

10. MILLIGAN KR, MACAFEE AL, FOGARTY DJ, WALLACE RG,
RAMSEY P: Intraoperative bupivacaine diminishes pain after lumbar discectomy. a randomised double-blind study. J Bone Joint Surg Br; 75(5):76971, 1993.

11. Durga P, Jonnavithula N, Khandelia H, Ramachandran G. Role of wound instillation with bupivacaine through surgical drains for postoperative analgesia in modified radical mastectomy. Indian $\mathbf{J}$ Anaesth 2015;59:15-20.

12. Margherita Bianconi et al. The Pharmacokinetics and Efficacy of Ropivacaine Continuous Wound Instillation After Spine Fusion Surgery. Anesth Analg 2004;98:166 -72.

13. Neha $T$ Das and Charulata Deshpande. Effects of Intraperitoneal Local Anaesthetics Bupivacaine and Ropivacaine versus Placebo on Postoperative Pain after Laparoscopic Cholecystectomy: A Randomised Double Blind Study. Journal of Clinical and Diagnostic Research. 2017 Jul, Vol-11(7): UC08-UC12.

14. Andrei Goldstein et al. Preventing Postoperative Pain by Local Anesthetic Instillation After Laparoscopic Gynecologic Surgery: A Placebo-Controlled Comparison of Bupivacaine and Ropivacaine. Anesth Analg 2000;91:403-7.

15. Saurabh Agrawal, Srinivas Pai. Evaluation of postoperative pain relief with intraperitoneal bupivacaine instillation in laparoscopic cholecystectomy-a randomized control study. Int Surg J. 2017 Apr;4(4):1195-1200.

16. B. I. Yolanda-Prieto, A. L. MillánCorrales, D. Palacios-Ríos, B. I. G arduñoChávez, N. G. López-Cabrera, G. A. Millán-Cornejo, B. T. González-Rocha. Iniltration vs. instillation of ropivacaine $7.5 \%$ in radical mastectomies for postoperative analgesia. Medicina Universitaria 2014;16(62):15-18. 